\title{
Ato analítico e a potência clínica do indeterminado*1
}

\section{Analytical act and the clinical power of the undetermined}

\author{
Fernanda Souza Adami*2 \\ Carlos Henrique Kessler*3 \\ Christian Ingo Lenz Dunker*4
}

Este trabalho visa discutir, no campo da teoria psicanalitica, uma articulação entre as noções de ato analítico e indeterminação. Parte da proposição lacaniana do ato analítico, para dar destaque à formulação chamada Grupo de Klein, apresentada como sequência transformativa, capaz de ilustrar os processos intrínsecos à experiência psicanalítica. Perpassa algumas considerações que Lacan extrai do cogito cartesiano, ao deslocar a categoria de sujeito da racionalidade positiva para a de um sujeito descentrado e evanescente. Finalmente, sublinha a característica indeterminada do ato como potência clínica para o reposicionamento do sujeito desejante. Dentro da perspectiva da direção do tratamento, situa a radical exterioridade do objeto causa do desejo do sujeito, resultando assim, o analista como resíduo das operações transformativas.

Palavras-chave: Psicanálise, ato psicanalítico, indeterminação, objeto $a$

*1 Artigo baseado na dissertação intitulada "Entre atos e hiatos: considerações acerca da potência clínica das experiências produtivas de indeterminação", apresentada em 2020 na Universidade Federal do Rio Grande do Sul - UFGRS. Trabalho realizado no Grupo de Pesquisa "Psicanálise e a clínica na universidade". Projeto "A pesquisa clínica em transferência”, vinculado ao Programa de Pós-graduação em Psicanálise: Clínica e Cultura da Universidade Federal do Rio Grande do Sul - UFRGS, sob coordenação de um dos autores, prof. Carlos Henrique Kessler. Também ao projeto de Pós-Doutorado "Acerca do reconhecimento na direção do tratamento", vinculado ao Programa de Pós-graduação em Psicologia Clínica da Universidade de São Paulo - USP, supervisionado por Christian I. L. Dunker.

*2, ${ }^{3}$ Universidade Federal do Rio Grande do Sul - UFRGS (Porto Alegre, RS, Brasil).

${ }^{* 4}$ Universidade de São Paulo - USP (São Paulo, SP, Brasil). 
Este trabalho versa sobre o conceito de ato analítico (Lacan, 1967-68/2001) e a dimensão de indeterminação da experiência. Como pergunta subjacente, tenta percorrer a perspectiva radicalmente clínica dessas noções: qual a potência do indeterminado na proposição lacaniana do ato analítico? Sustentamos como hipótese fundamental que a experiência de descentramento subjetivo precipitada pelo ato carrega, em si, a potencialidade de ressituar a condição desejante daquele que padeceria de uma cristalização narrativa.

Procuraremos pôr em evidência teorizações que perfazem o caminho lacaniano acerca da operatividade da psicanálise, recorrendo a uma retomada das questões contidas no seminário do ato analítico, de 1967-68 de Jacques Lacan. Destacamos a perspectiva descentrada contida na categoria de sujeito, bem como a utilização do recurso do Grupo de Klein proposto pelo mesmo, como forma de evidenciar os passos de um percurso analítico. Ainda sublinharemos a característica indeterminada do conceito de objeto $a$ no que tange à direção do tratamento.

\section{Uma breve apresentação do conceito de ato em Lacan}

Lacan começou seu seminário sobre o ato analítico em 15 de novembro de 1967. Ali ele mencionou a estranheza que alguns poderiam ter em relação a este par de palavras: ato psicanalítico. Se, desavisadamente, tomarmos o entendimento do termo ato como um sinônimo de ação tão somente, logo aí, o espanto em relação à prática da psicanálise se mostraria pertinente, já que Freud desaconselhava seus pacientes a tomar qualquer tipo de atitude com maiores implicações ao estarem em análise. Desse ponto de vista, seria de imaginar que associar a palavra ato exclusivamente ao campo da ação, poderia incorrer em uma interpretação equivocada. 
Contudo, Lacan pretendia chamar a atenção para outra direção. Entendemos que ele chega a fazer certa subversão da palavra na maneira como a usa. Partindo do que seriam os "atos humanos", ele provoca uma suspensão da ordem significante e considera a polissemia do termo, apresentando o ato como o que faz ruptura e inaugura uma nova cadeia significante.

Logo, uma ação pode, sim, ter o estatuto de ato se dela derivar uma ruptura com o instituído. Lacan nos diz: "se posso caminhar aqui, de um lado para outro, falando, isso não constitui um ato, mas se um dia ultrapassar certo limiar onde me coloque fora da lei, esse dia, minha motricidade terá valor de ato" (Lacan, 1967-68/2001, p. 14).

Inspirado pelos fatos históricos do Império Romano, Lacan ilustra o que estava querendo introduzir, invocando a travessia do rio Rubicão por Júlio César. Em 49 a.C., o rio que era na verdade, um pequeno curso d'água, demarcava a fronteira entre a Gália Cisalpina e a cidade de Roma. Do ponto de vista geográfico sua importância era ínfima. No entanto, a proibição de que qualquer general o atravessasse com seus exércitos, vinha da intenção de impedir que grandes contingentes de soldados fossem em direção ao território romano onde o poderio do império ficava concentrado.

Ao atravessar propositalmente a fronteira simbólica na perseguição a Pompeu, César viola a lei. Consta que na ocasião teria proferido a seguinte frase: Alea jacta est ("o dado foi lançado", em latim). Essa frase passou a ser evocada em muitos momentos em que alguém toma uma decisão de caráter irrevogável, com implicações incertas. Atentemos para a perspectiva indeterminada que ela contém, pois é pela via do franqueamento das barreiras da lei instituída que se dá a condição de acesso à via do desejo, mesmo que não se tenha garantias dos seus desdobramentos.

Se já distinto o fazer do que implicaria uma atitude pura e simples, a menção de que, assim como a poesia, a psicanálise "isso faz", poderia nos dar uma pista da perspectiva indeterminada que compõe o ato. $\mathrm{O}$ poema em questão é aquele que Arthur Rimbaud nomeou A uma razão, de 1886 e que Lacan (1967-68/2001) apontou como a "fórmula do ato analítico" (p. 78). Vejamos os versos:

\section{À UNE RAISON}

Un coup de ton doigt sur le tambour décharge tous les sons et commence la nouvelle harmonie.

Un pas de toi, c'est la levée des nouveaux hommes et leur en-marche.

Ta tête se détourne: le nouvel amour!

Ta tête se retourne: le nouvel amour! 
Change nos lots, crible les fléaux, à commencer par le temps, te chantent ces enfants.

Élève n'importe où la substance de nos fortunes et de nos vœux, on t'en prie.

Arrivée de toujours, qui t'en iras partout. ${ }^{1}$

(Rimbaud, 1871; tradução nossa)

Esses versos, por mais de uma vez evocados nos seminários, refletem a dimensão do novo; tentam ilustrar como acontece o que poderíamos chamar de uma força transformativa que mobiliza o humano. Um novo desejo na medida em que, ao se deparar com esse ponto de fuga fundamental, o sujeito teria de se haver com a invenção de um rearranjo na cadeia associativa, com uma alteração na sequência significante.

Se a determinação da estrutura não garante que a ordem do discurso se mantenha através do encadeamento das frases evocadas para produzir um sentido, a escansão da linguagem como corte nesse sentido, o chamado pas-de-sens (sem sentido/passo de sentido), acaba por fazer acento nos intervalos das unidades mínimas (Torres, 2013), conferindo a eles a importância da dimensão da indeterminação em qualquer movimento capaz de produzir, para estar com Lacan, uma "revolução".

As formações do inconsciente, como os atos falhos, chistes, sonhos, sintomas e a própria repetição significante, apontam para esse hiato no processo de simbolização e por isso mesmo constituem um campo: o campo de trabalho do psicanalista. Esse âmbito estaria posto na medida em que uma função, determinada por uma posição discursiva, fizesse valer um efeito capaz de ultrapassar as formações sintomáticas na direção do encontro com o desejo.

O que veicula essa posição discursiva é a fonte de relação que comumente chamamos de transferência. Seguindo em sua apresentação do ato analítico, nosso autor destaca que já em outros tempos, de maneira não

${ }^{1}$ Um toque de teu dedo no tambor desencadeia todos os sons e dá início a uma nova harmonia. / Um passo teu, recruta novos homens, e os põe em marcha. / Tua cabeça se vira: o novo amor! / Tua cabeça se volta, - o novo amor! / "Muda nossos destinos, acaba com as calamidades, a começar pelo tempo", cantam estas crianças, diante de ti. / "Semeia, não importa onde, a substância de nossas fortunas e desejos", pedem-te. / Chegada de sempre, que irás por toda parte. (Rimbaud, 1871; tradução nossa). 


\section{ARTIGOS}

formulada, havia anunciado que a transferência "é a colocação em ato do inconsciente" (Lacan, 1967-68/2001, p. 11). Para Lacan, não há ato sem transferência, pois ela carrega a força do saber depositado no analista e precisamente quando essa esperança se torna decepção é que o ato de passagem se efetiva.

Considerado por Lacan como um dos quatro conceitos fundamentais da psicanálise, a transferência é apresentada por Freud, desde os primórdios, como um fenômeno determinante para a clínica. Entendida como a reatualização da realidade do inconsciente (Lacan, 1964/1998b), ela torna-se campo para as intervenções que advirão do analista, bem como a possibilidade de atravessamento das questões do sofrimento psíquico que serão depositadas como demanda sob aquele que ocupa essa função.

A partir da conceitualização da transferência, a entrada em análise constitui um ato, onde a expectativa do saber suposto ao analista, permite que o analisante busque romper com a repetição significante abrindo espaço para, a partir desse laço, inventar uma nova posição subjetiva.

Lacan abordou o tema do ato analítico pelas vias do estar analisante e do tornar-se analista. De um lado, o ato é do analista ao estabelecer a operação analítica. Ele é um primeiro momento do ponto de vista do analisante, que está alienado nessa operação. De outro, é do analisante, ao depor, destituir o analista, que se reapropria do que lhe concerne por seu ato. Aquela operação é primeira para o analisante, e segunda, por efeito retroativo, para o analista. Ao tentar formalizar a experiência analítica através da noção de ato analítico, Lacan deixa antever o fracasso inerente a qualquer posição que implique uma nomeação permanente e isso, mais uma vez, nos remete à questão da indeterminação.

Desta nova posição deriva, então, o momento nuclear que Lacan refere à irrupção do ato: o final da análise, a queda da condição de sujeito suposto ao saber no/do analista, com a decorrente passagem do analisante a eventual analista. A instalação de alguém nessa posição discursiva, depende de que, pelo ato de atravessamento dos processos de identificação e advertido da condição de alienação promovida pela captura do Outro (instância designada como a morada dos significantes), o sujeito possa sustentar para um outro o percurso de encontro com seu desejo.

Lacan nos diz: o que é próprio do ato analítico é uma condição radicalmente paradoxal, que consiste "em que alguém possa fundar uma experiência sobre pressupostos que ele mesmo ignora profundamente" (Lacan, 1967-68/2001, p. 19). Atentemos para o fato de que essa frase também carrega consigo a dimensão indeterminada que o ato analítico comporta. Fundar uma experiência naquilo que se desconhece, implica uma condição 
de descentramento tal, só passível de ser posta em ato se o próprio analista decantou de seu percurso uma experiência de destituição subjetiva.

A destituição subjetiva é apresentada no seminário como o destino necessário da operação do ato. Àquele que, nos mais diferentes momentos da análise, se deixa afetar pelo ato, é dada a experiência da queda de determinadas coordenadas simbólicas e essa operação permite certo reposicionamento diante do Outro da linguagem.

Mas cabe aqui um apontamento. Lacan, pretendendo advertir da facilidade de tornar esse percurso algo idealizado, vai ainda mais longe quando afirma que, na verdade, o psicanalista tem horror do seu próprio ato. Horror justamente por desconhecer a dimensão daquilo que se propõe a ser objeto; pela indeterminação que aí se precipita, sendo apenas portador dessa marca. A marca de ter verificado a inconsistência do Outro.

O aspecto técnico também se apresenta através das intervenções clínicas nomeadas como corte; mas ao que parece, poderíamos dizer que nessa discussão, esse aspecto seria colateral, já que a perspectiva ética se sobrepõe aos parâmetros do como fazer e particularmente em se tratando do ato, jogamos com a impossibilidade de antecipação.

Diferentemente de Freud, que tinha como preocupação inscrever a psicanálise na tradição científica de sua época, e que se esforçou para percorrer os caminhos que denotassem um mínimo conjunto de procedimentos a serem seguidos, Lacan apresentou o campo psicanalítico como uma ética em primeiro lugar. Não que deixasse de lado a formalização, coisa que podemos perceber muito bem pelo uso das matemáticas e das lógicas formais, mas esta tinha a intenção de suprimir o espaço significante e dele decantar a dimensão que veio a chamar de Real.

Dentro dessa dinâmica, sob a perspectiva lacaniana, a técnica ficou subordinada a esse atravessamento ético que o desejo impõe ao sujeito. Há um impossível de recobrir com a linguagem e esse impossível remete diretamente à dimensão negativa que muitos conceitos psicanalíticos comportam. Especialmente nos referimos à categoria de sujeito, que subverte as proposições cartesianas e apresenta esse sujeito como descentrado.

\section{Da racionalidade cartesiana ao "não penso ou não sou"}

Desde muito cedo em seu ensino, Lacan tomou o Cogito cartesiano como referência para suas formulações. Por exemplo, no texto "A instância 


\section{ARTIGOS}

da letra no inconsciente ou a razão desde Freud" de 1957, ele vai, através do Cogito, introduzir a função de sujeito a partir do inconsciente estruturado em termos de metáfora e metonímia, como uma linguagem (Lacan, 1957/1998). Mas é no seminário que antecede ao do ato psicanalítico que ele chega a desenvolver de forma mais detida a sua leitura da proposição de Descartes.

Cogito ergo sum ou Penso logo sou/existo determina que a condição de existência está dada pela faculdade do pensar. Portanto, se posso duvidar, estou assegurado dessa certeza. Este axioma representa o estatuto fundamental da consciência e sob esta égide se organizou todo o pensamento moderno baseado na supremacia da razão e suas consequências para o campo científico.

Se Descartes procurava uma garantia universal para a sustentação do conceito de verdade, Lacan viu nessa lógica uma dobra fundamental que lhe permitiu destacar o estatuto do inconsciente, ainda que afirmasse que só mesmo a partir do nascimento da ciência no século XVII o sujeito da psicanálise pôde surgir.

Ao tomar o Penso logo sou/existo pelo avesso, Lacan passou a propor a estrutura do inconsciente dentro de uma operação de negação extraída das leis de Morgan, que afirmam que: (1) a negação da conjunção de duas proposições é logicamente equivalente à disjunção das negações das duas proposições consideradas e (2) a negação da disjunção de duas proposições é logicamente equivalente à conjunção das negações das duas proposições consideradas. Lacan opera uma disjunção fundamental ao separar o ser do pensamento. $\mathrm{O}$ inconsciente aparece como o efeito dessa ruptura.

Assim foi possível postular o não penso ou não sou como o avesso do penso logo sou cartesiano. Atentemos para o fato de que não se trata de seu contrário, mas de seu avesso. Esta máxima permitiu passar de uma proposição inclusiva representada pelo Cogito, para uma proposição exclusiva conforme o sou onde não me penso, por isso onde me penso, não sou.

O conectivo ou chama a atenção entre as premissas envolvidas acima. A proposição exclusiva presente ali é essencial para a formalização do conceito de ato que Lacan fará a partir do Grupo de Klein a ser apresentado mais adiante. Ele, o conectivo ou, comporta a ideia de que há uma passagem de um ponto a outro e isto denotaria nada menos do que o lugar da direção do tratamento dentro da sequência transformativa. Ao mesmo tempo, carrega consigo uma disjunção que impede que a ação do pensamento ocorra concomitantemente à realização subjetiva.

Conforme Lacan nos apresenta no seminário $O$ avesso da psicanálise (1969-70/1992) a fórmula de que o sujeito não é unívoco, “ou não penso ou 
não sou” (p. 96) nos foi dada no seminário sobre o ato analítico. E segue: “[...] o sujeito é posto diante desse vel que se exprime pelo ou não penso, ou não sou. Ali onde penso não me reconheço, não sou - é o inconsciente. Ali onde sou, é mais do que evidente que me perco" (p. 96).

Torres (2010) chama a atenção para a noção de vel (ou, em latim) referida por Lacan no Seminário XI de maneira distinta e retomada aqui em sua relação com o Cogito. Naquele momento anterior, o vel estava ligado ao "ser" e ao "sentido" a partir das operações de alienação e separação na constituição do sujeito. Agora no Seminário XV, ele aparece em termos das operações alienação e verdade, que em sua relação com a proposição cartesiana, permitem demonstrar os destinos possíveis dentro da lógica exclusiva.

Ainda segundo Torres, essas operações "criam o vel, fazendo passar o não penso e não sou, ao não penso ou não sou" (Torres, 2010, p. 178). Mantida a relação de exclusão, interessa a intersecção pela negação do Cogito. É pela reunião do não ser com o não pensar, que se promove uma subversão, particularmente lacaniana, ao formalizar, através do Grupo de Klein no Seminário XV, a experiência de análise.

Se é dado ao sujeito, depois de ter passado pela experiência de análise, 550 a posição de ter atravessado as fronteiras dos processos identificatórios em direção a uma não submissão completa e alienante ao Outro da linguagem, é preciso perceber que ela não é fixa e estabelecida. Entendemos que precisamente aí reside um cuidado, já que essa menção pode denotar que ao final de um percurso analítico, seria possível vivenciar a queda de todas as identificações. Talvez o destaque devesse se dar mais propriamente para o fato de que o atravessamento da fantasia teria um caráter estruturante, na medida em que adverte o sujeito para um ponto que está posto fora da fantasia, não sendo mais possível (ex)sistir fora dela.

Pensar que alguém possa aceder a uma condição de analisado seria um contrassenso se pudermos observar que tomar este dito lacaniano como verdade em si, também seria um tipo de ideal erigido. No seminário do ato psicanalítico, Lacan diz que não há psicanalisado, mas sim, um "tendo sido psicanalisante" (Lacan, 1967-68/2001, p. 64). Ele descreve assim o destino de um tratamento, utilizando o gerúndio condicional para demarcar as consequências do ato na torção do rumo da posição subjetiva. Implica uma noção de movimento e de passagem que talvez nos diga o quanto uma posição idealizada iria na contramão do que estava tentando propor.

Tendo isso em vista, acreditamos que essa discussão poderia ser mais produtiva se atentarmos ao destaque que Lacan deu ao termo destituição 


\section{ARTIGOS}

subjetiva. Esse termo não implica uma perspectiva idealista, como se no horizonte houvesse um lugar a ser alcançado por aquele que percorreu o "caminho das pedras", mas sim demarca uma condição de suspensão do excesso de determinação operado pelos processos identificatórios.

Estar destituído subjetivamente implica, segundo Menegassi (2010) em dissertação específica sobre o tema:

[...] dizer que o sujeito, na análise, vai desde a sua instituição enquanto incógnito ou corte, até a sua destituição enquanto sujeito que elabora e aceita a perda da indeterminação interminável através do efeito de castração. [...] Dentro deste regime, para Lacan a destituição subjetiva seria o equivalente da travessia da fantasia, sendo a fantasia aquilo que faz com que o sujeito creia que a subjetivação total seja possível. (pp. 53-54)

Dessa forma, é justamente a direção contrária que Lacan nos aponta, na medida em que, estando advertido de sua castração, o sujeito poderia fazer uma aposta desarticulada da posição de saber, ou seja, destituída do excesso de colagens imaginárias e, então, abrir espaço para a invenção de uma nova posição.

\section{O Grupo de Klein com o ato no eixo contrário da transferência}

Foi na formulação sobre o Grupo de Klein que Lacan nos apresentou ao que entendemos aqui como uma possibilidade de formalização dos processos transformativos ocorridos na experiência psicanalítica. Extraído de um recurso matemático proposto por Marc Barbut (1966) no artigo intitulado "Sobre o sentido da palavra estrutura nas matemáticas", Lacan, a seu modo, propõe utilizar esse modelo matemático para pensarmos os passos de uma análise.

A utilização do recurso do Grupo de Klein vem desde o seminário do ano anterior. Em A lógica do fantasma, Lacan (1966-67/2008a) apresenta, a partir do texto freudiano "Uma criança é espancada" (Freud, 1919/2010), a divisão constituinte provocada pela fantasia através da operação alienação. Esta explora o fato de o sujeito não se reconhecer em um desejo que na verdade é seu. A montagem da fantasia se apresenta aqui também como um ato.

A Figura 1 a seguir, aparece como uma elaboração lacaniana na apresentação da aula do dia 10 de janeiro de 1968. Essa figura já vinha sendo trabalhada até mesmo no seminário anterior (Lacan, 1966-67/2008). Na forma de um tetraedro, Lacan estabelece quatro posições representadas pelos círculos 
de Euler, e dessas quatro posições ele deriva três operações (alienação, verdade e transferência).

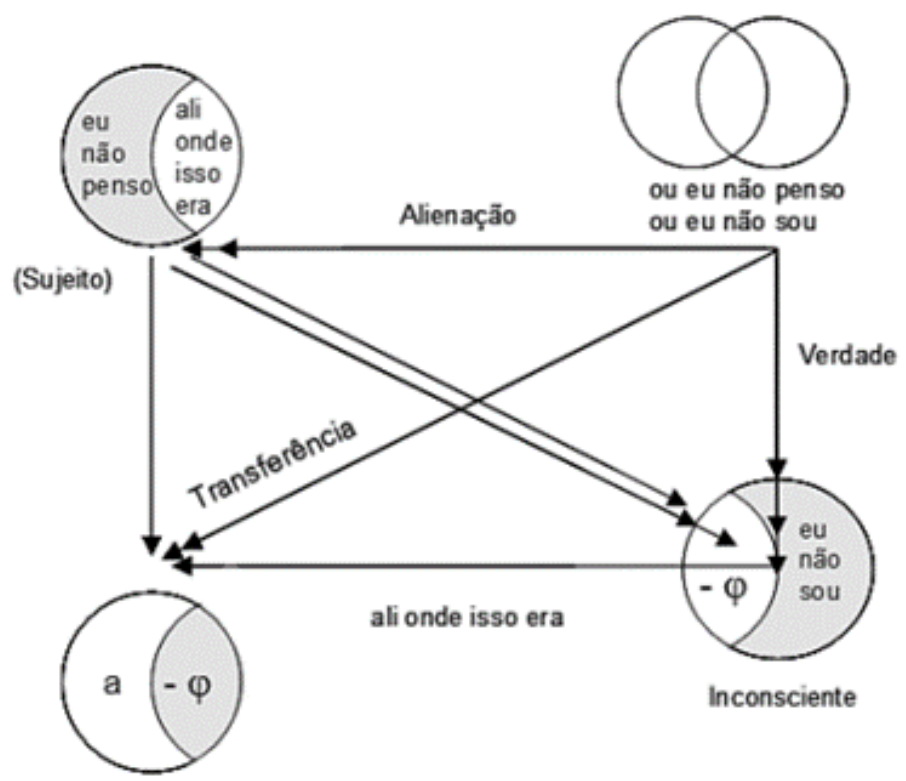

Figura 1

É importante destacar que não à toa a figura é de um tetraedro, pois em sua especificidade ela impede o excesso de esquematização já que se organiza em três dimensões no espaço. De acordo com Dissez (2005), "com esses quatro lugares e essas três operações, temos algo como uma bateria mínima que permite dar conta da alienação fundamental do sujeito e da possibilidade de que haja ato psicanalítico" (parag. 20). O fato de apresentar o Grupo de Klein como uma formalização tridimensional, permite destacar a importância de não se tomar o tratamento a partir de um excesso de esquematização.

Nas Figuras 2 e 3, optamos por apresentar o Grupo de Klein proposto por Lacan, dividido em quadrantes como forma de percorrer textualmente a formulação. Da esquerda para a direita, os quadrantes são dispostos conforme o movimento intrínseco aos processos transformativos nele localizados. 


\section{ARTIGOS}

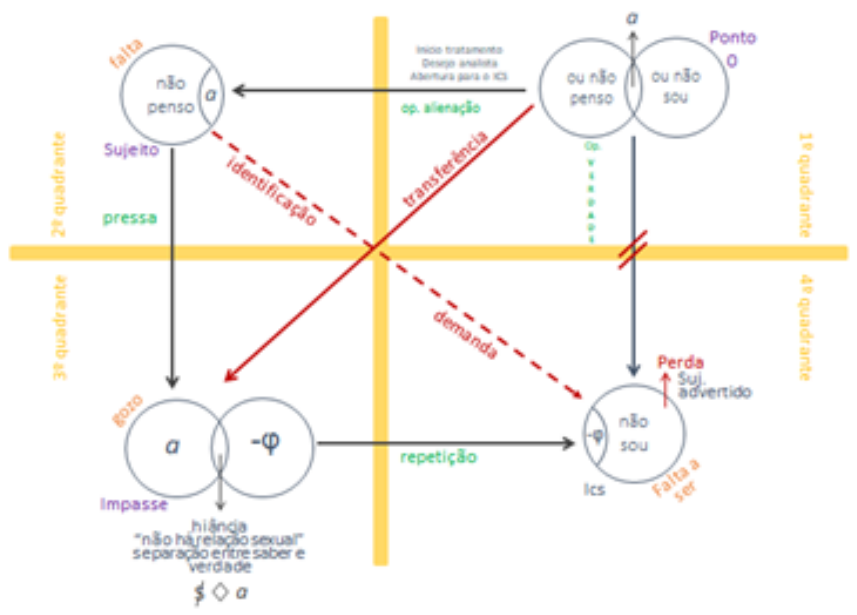

Figura 2

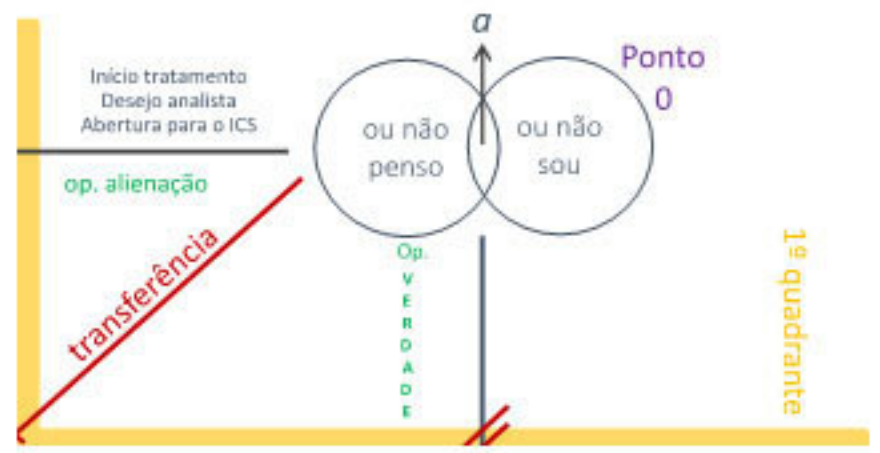

Figura 3

Analisando separadamente os diferentes quadrantes, podemos observar que, no primeiro, situado acima e à direita, encontramos o ponto 0 (zero) (Figura 3). O ponto onde dois conjuntos: o ou não penso e o ou não sou, se 
interseccionam no momento inicial. Três vértices partirão dessa formação: o vértice da operação alienação, o da transferência e da operação verdade.

No primeiro vértice (na flecha superior, da direita para a esquerda), Lacan localiza a operação alienação, o primeiro passo, o momento inicial da análise, aquele que a partir de uma abertura para o inconsciente, o desejo do analista em escutar, põe em funcionamento o início do tratamento.

Segundo Torres (2010), à operação alienação, Lacan associa uma escolha forçada no sentido que demarca a radicalidade da posição ética como uma tensão entre determinação e liberdade, "uma decisão diante do indecidível" (p. 180).

Seguimos acompanhando a figura, agora localizada no segundo quadrante (Figura 4).

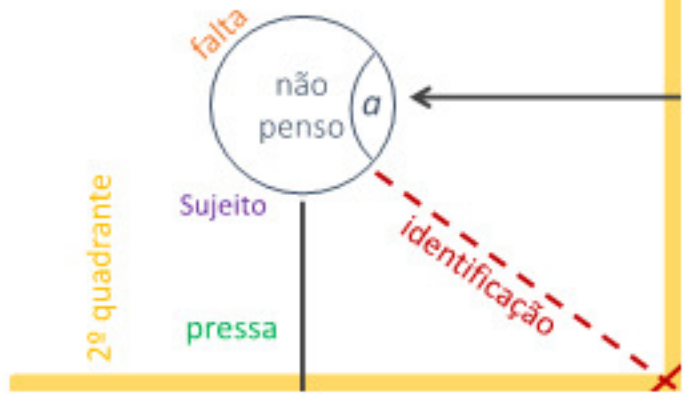

Figura 4

$\mathrm{O}$ vértice acima e à direita no primeiro quadrante da Figura 2, deriva para o segundo conjunto onde, por exclusão do conjunto não sou, se apresenta apenas o não penso como elemento inicial de aparição de um sujeito dividido pela falta constituinte. Ele carrega consigo a marca do objeto causador do desejo.

Esse momento preambular se caracteriza pelo início de um percurso analítico, já que o sujeito se vê instalado em uma dimensão de enigma em seu sofrimento, que o faz se perguntar sobre o que o determina. Poderíamos caracterizá-lo como o tempo das primeiras entrevistas, ou associando com a formulação do tempo lógico, um instante de ver. 


\section{ARTIGOS}

Do conjunto não penso, no segundo quadrante, derivam dois vértices onde, de um lado, a função da pressa, como vimos nas considerações sobre o tempo lógico, precipita um movimento em direção ao ou do quadrante inferior (Figura 5).

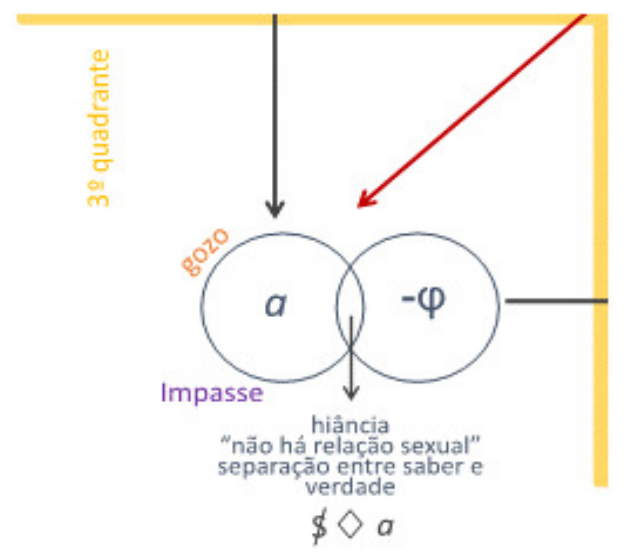

Figura 5

Este ou, localizado no terceiro quadrante, contém a intersecção que representa o impasse da confrontação entre o objeto que causa o movimento desejante e o elemento, deduzido da divisão subjetiva, chamado por Lacan, - $\boldsymbol{\varphi}$ (menos phi, letra grega minúscula, referência à perda do falo em sua dimensão imaginária). Nesse elemento apresentado como o lugar do impasse, poderíamos localizar o conceito de gozo, tão importante na obra lacaniana por substancializar o modo como o sujeito se defende do encontro com o desejo.

Nesse mesmo quadrante, entre o conjunto $a$ e o conjunto $-\boldsymbol{\varphi}$, encontramos uma intersecção caracterizada pela hiância que representa a não complementaridade da relação sexual de acordo com o axioma lacaniano. A disjunção entre saber e verdade, formalizada por intermédio da fórmula da fantasia $(\$<>a)$ demonstra o quanto a obturação pelo saber impossibilita ao sujeito o encontro com a verdade. De acordo com Kessler (2009):

Ao final destes vários movimentos, temos uma espécie de balanço da posição de Lacan a esse respeito, situando a fórmula do sujeito na fantasia, com a célebre definição do operador $<>$ (punção) e uma nova caracterização acerca 
do $a$, enquanto o que resiste à significantização, fundamento (e, portanto, causa) perdido do sujeito desejante. (p. 47)

Desse terceiro quadrante prossegue o vértice da repetição. Conceito fundamental, a repetição aparece como o movimento no qual o sujeito ficaria preso no tempo de compreender. Tendo se deparado com a falta de complementaridade do objeto, a tentativa de restituição vai produzindo voltas na demanda. O eu não se reconhece, pois ocorreria certa disjunção entre o lugar da verdade e o saber inconsciente.

Para voltarmos um pouco nessa descrição, ainda derivada do segundo quadrante (Figura 4) no conjunto não penso, podemos localizar o vértice que vai dessa diagonal esquerda superior, para o conjunto diametralmente oposto, localizado no quarto quadrante (Figura 6).

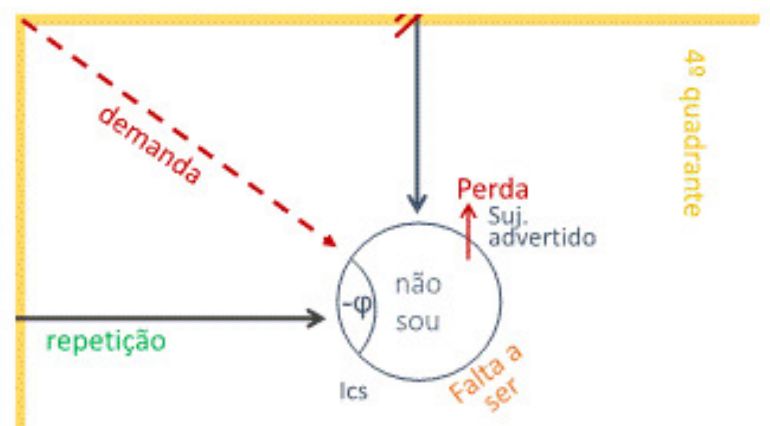

Figura 6

Esse vértice parte de um caminho inicialmente denominado como identificação e ao atravessar a diagonal contrária, onde Lacan localiza a transferência, passa a operar como demanda em direção ao lugar do conjunto não sou.

Esse conjunto, o lugar da falta a ser, poderíamos situá-lo como o próprio lugar do inconsciente. Aquele que, desde uma operação de perda, produz o sujeito advertido de sua condição faltante. Eis o destino último da sequência transformativa que por redução ao penso onde não sou por isso sou onde não me penso, impõe ao sujeito a condição paradoxal da "escolha forçada", ou seja, escolher sustentar o desejo para além da garantia do Outro. 


\section{ARTIGOS}

Voltando ao primeiro quadrante (Figura 3), não deixemos de observar que a operação derivada do vértice que vai do conjunto ou não penso/ou não sou ao conjunto não sou (localizado no quarto quadrante) denominada operação verdade, aparece barrada ao seu acesso imediato. É nesse ponto que a formulação lacaniana difere da proposta pelo matemático Marc Barbut, pois para este, a sequência transformativa permitia uma involução que no grupo de Lacan não aparece como possível. Essa impossibilidade está dada justamente pelo fato de que não é possível ao sujeito retornar a uma posição em que não resta advertido de sua alienação constituinte.

Por conta dessa característica não involutiva, vemos na formulação de Torres (2010) sobre o ato analítico, uma apresentação do Grupo de Klein lacaniano como um semigrupo. "Ao definir seu esquema como um semigrupo, sabendo disso ou não, Lacan livra-se de um dos axiomas do grupo de Klein” (p. 178), ou seja, a condição não involutiva (que, como nos aponta Torres, em Lacan é decididamente involutiva já que não é possível voltar ao mesmo ponto), fica resguardada. Se não fosse assim, o sujeito permaneceria como esteve até então, determinado pela condição de repetição.

Cabe aqui uma observação pontual acerca da cronologia implícita na sequência transformativa. Na figura apresentada por Lacan (Figura 1), vários vértices partem e chegam em mais de uma direção possível. Em nossa descrição (Figuras 2 a 7), suprimimos os variados vértices não como forma de desconsiderá-los, mas sim para fins didáticos, visto que nos permitiu organizar a sequência de forma explicativa. Concordamos com Vegas (2013), quando nos apresenta que:

Apesar de Lacan indicar um percurso em $\mathrm{Z}$ espelhado, nada indica que isso ocorra apenas neste sentido e numa sequência cumulativa, pois isso implicaria primeiro que fossem trabalhadas todas as identificações para então se adentrar no campo da verdade. Como se pode ver no tetraedro, da posição inicial partem setas em todos os sentidos, marcando as diversas possibilidades de movimento que ocorrem na análise. (pp. 102-103)

Pois eis que aqui temos elementos para acompanhar onde Lacan localiza $\mathrm{o}$ ato analítico dentro da sequência. $\mathrm{O}$ vértice do ato estaria localizado no quadrante do impasse em direção ao quadrante do ponto zero (conforme Figura 7), ou seja, na intersecção entre a negação do pensar e do ser.

Seria justamente fazendo o percurso inverso ao da transferência que o ato analítico, como um movimento capaz de disrupção do laço transferencial, possibilitaria a queda das coordenadas sustentadas pelo sujeito suposto 
saber. Do gozo à extração do objeto radicalmente vazio, o objeto $a$, conforme veremos a seguir.

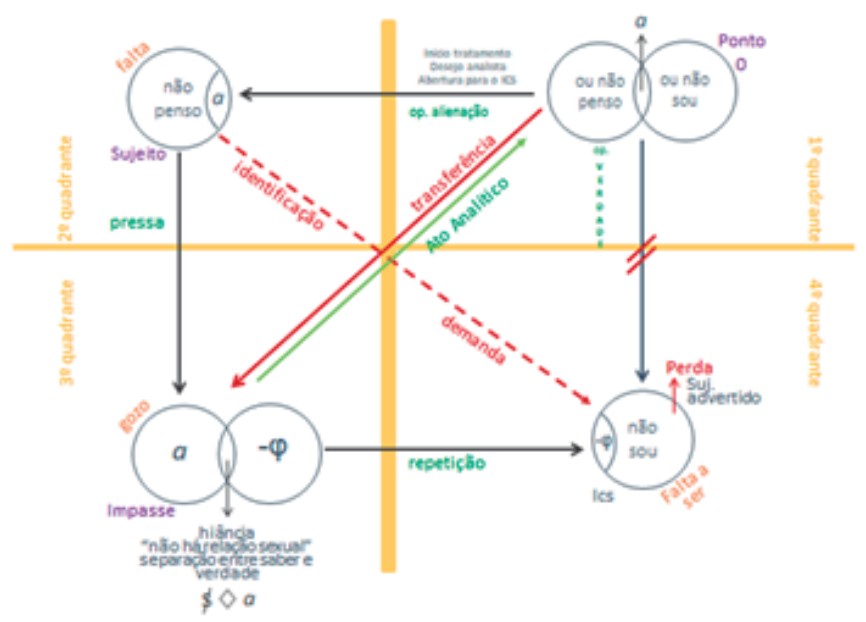

Figura 7

\section{A não relação evidente no ato e sua dimensão de indeterminação}

Se Lacan nos apresenta no seminário XIV - A lógica do fantasma (1966-67/2008), a partir do axioma "não há relação sexual", que a impossibilidade de todo encontro já está dada de saída em qualquer posição discursiva, podemos daí fazer observar que o que o ato analítico evidencia é justamente essa não relação.

Esta observação pode ser recolhida, por exemplo, na distinção que Torres (2013) faz entre o ato sexual e o ato analítico:

Lacan passa a mencionar que, com relação ao "ato sexual", ele não há. Expressão que condensa pelo menos duas concepções fundamentais em nosso entender. Em primeiro lugar porque se articula à ideia de que a fantasia é uma tentativa de fazer acontecer o ato que faria a conjunção dos sexos, mas que, ao invés disso, liga apenas um sujeito a um objeto que materializa a impossibilidade da conjunção aspirada. É por isso que Lacan pode dizer nesse momento que não há ato sexual. Em segundo, porque aponta que o que pode haver é o 


\section{ARTIGOS}

ato psicanalítico, que vai em sentido contrário ao tipo de laço que o ato sexual busca alcançar, na dimensão mesma dessa separação entre um real articulado ao objeto pulsional e um real para além dessa articulação. (p. 42)

Como vimos a partir dessa definição, um movimento de ruptura das coordenadas simbólicas precisa acontecer para que o sujeito emerja sob um outro balizamento significante, um rearranjo da cadeia. Lacan situa nesse momento o registro da perda (que também pode ser observada acima na Figura 4). É esse acordo impossível com a instância do Outro, marcado de forma irredutível pela perda, que Lacan assinala na sequência do Grupo de Klein com o $-\boldsymbol{\varphi}$, já que se trata de uma perda referente à castração.

Isso indica uma operação lógica. Dela deriva o sujeito que não é nada mais do que o efeito de relação com sua própria palavra já que impotente em reconstituir o objeto de completude. Mas se estamos tentando contornar o incontornável, e se só podemos acessá-lo pelos seus efeitos, é importante sublinhar certa negatividade que aparece como central nessa teorização.

Como dissemos acima, o ato analítico pressupõe uma condição de indeterminação e queremos crer que a queda dos determinantes simbólicos ocorrida pela precipitação de uma experiência de descentramento contida no ato, carrega em si uma potência clínica capaz de alinhar o sujeito com sua condição desejante. Mas como e por que isso acontece? Comecemos pela disjunção que Lacan faz entre os termos saber e verdade.

Já em 1965, no seminário sobre o objeto da psicanálise, podemos perceber uma distinção que será retomada em 1967 pela via da proposição do ato. Associada às considerações do Cogito cartesiano, Lacan (1967-68/2001) vai apresentando, a partir da derivação de definições aristotélicas sobre a causalidade, a ideia de que a verdade é sempre causa do saber e não que o saber é necessariamente construído sob o pilar da verdade. Isto, no entanto, não é imediatamente apreensível para o sujeito, já que a divisão constituinte o impede de aceder sobre o que seria a verdade do seu desejo.

Partindo de uma construção sobre os tipos de saber, Lacan vai fazendo uma distinção entre os modos que esses saberes atuam no mundo. Na religião, na magia, na ciência e na psicanálise, temos formas diferentes de operar com a verdade, ainda que todas elas tenham apenas uma verdade como causa, a verdade do inconsciente.

Tomando o sujeito da ciência como paradigma para exemplificar o que estava propondo, segundo já desenvolvemos sobre a racionalidade cartesiana, Lacan não diferencia este, do sujeito da psicanálise. No entanto, subverte seu significado na medida em que o desassocia do conceito de consciência e o 
apresenta como submetido às regras da linguagem, articulando-o a uma teoria do significante. É no deslizar da cadeia que esse sujeito emerge como um efeito e isso propriamente evidencia sua divisão, pois é desde um significante primordial que o representa, que um outro pode surgir. Isto, no entanto, ao mesmo tempo que estabelece uma articulação, promove seu apagamento.

Partimos desse ponto para aproximar ainda mais o conceito de ato analítico da ideia de indeterminação. A divisão constitutiva traz de saída uma hiância, um entre, que poderíamos ler como o primeiro elemento de indeterminação em uma estrutura marcada pela tentativa repetida de restauração. Restauração esta que Freud leu como compulsão à repetição e pôde daí postular o conceito de pulsão de morte, desenvolvido amplamente no texto “Além do princípio do prazer" (1920) (Freud, 1917-1920/2010). Lacan, por sua vez, a destacou a partir do conceito de objeto $a$.

\section{O objeto sem substância: a negatividade do conceito de objeto a}

O conceito de objeto $a$ na obra lacaniana tem papel fundamental. Na verdade, Lacan (1966-67/2008a; 1968-69/2008b; 1971/2009) chegou a dizer que sua única verdadeira contribuição à teoria psicanalítica adveio da postulação do conceito de objeto $a$. Sendo assim, é importante que possamos percorrer suas definições, bem como sua operacionalidade no que tange ao encadeamento das noções de ato analítico e indeterminação.

Assim como o conceito de pulsão em Freud, a noção de objeto $a$ em Lacan parte de uma radicalidade limítrofe. Radicalidade na medida em que estabelece uma fronteira capaz de circunscrever toda a extensão da teoria psicanalítica. Em artigo, Kessler defende sua radicalidade não b(analisável). Como conceito central, produz um ponto de inflexão que diz do fato de o sujeito ser comandado por algo que é externo a qualquer definição possível de objetividade, um lugar exterior a qualquer tentativa de interiorização (Kessler, 2008).

A definição do conceito de objeto $a$ é dada pelo axioma "objeto causa de desejo". Enquanto causa pode ser colocado nessa posição exterior mencionada acima e ao mesmo tempo, como um ponto de perda fundamental que acaba por promover o movimento significante.

Foi a partir do seminário $O$ desejo e sua interpretação (1958-59/2016) que a noção de objeto $a$ foi adquirindo cada vez mais estatuto de conceito. Antes disso, a letra "a" minúscula era apenas usada para designar, no 


\section{ARTIGOS}

Esquema L, os objetos do eu (moi) ou por vezes, até mesmo o eu ( $\mathrm{Je})$ e ainda mais especificamente, o outro semelhante (autre), aquele que se distingue do Outro.

Foi no seminário dos anos 1962 e 1963 que Lacan desenvolveu, de forma mais detida, suas considerações sobre esse conceito essencial. Utilizar a letra $a$ para nomear o ponto radicalmente exterior a todo sujeito (mas que o define nuclearmente), tem a sua razão. Ela é intraduzível (e portanto, indeterminada) e comparece, nas mais diferentes línguas, como a primeira letra, e no entanto, não designa sentido algum. Ela é, como nos diria Porge (2009), "algébrica" (p. 239). Ele segue:

A intraduzibilidade de $a$, pela qual me parece que seja preciso optar, é talvez, uma das marcas de sua invenção. A invenção seria intraduzível de uma língua para outra; ela não passaria pelos desfiladeiros do sentido (autre $=$ otro $=$ other) por uma operação preliminar de equivalência do sentido, preliminar à amostra literal. Entretanto, este conserva o selo de origem, umbilical, de sua ligação com a língua francesa. Mas, uma vez feito o corte, ela não mais se dá a refazer, e é a mesma letra que é destinada a circular em todas as línguas, podendo, aliás, quando for necessário, tomar ressonâncias particulares. (p. 239)

Lacan (1962-63/2005) toma o objeto $a$ como sua invenção, ou seja, um efeito de discurso, do discurso analítico mais especificamente. O conceito põe no horizonte a ex-centricidade do sujeito tomando a letra mais indeterminada como objeto, definida pela sua negatividade.

Não representável no mundo, o objeto $a$ é apenas passível de dedução, sempre caracterizado por sua dimensão de falta-a-ser, que comparece na medida em que, investido libidinalmente através de fragmentos parciais reduzidos por Lacan em seio e fezes, objetos de sucção e de excreção, respectivamente e ainda, voz e olhar, como objetos do desejo.

É pela falta de especularidade característica do objeto $a$, um objeto sem ponto de fixação imagética, que podemos ter uma verdadeira notícia da importância da noção de indeterminação no ensino lacaniano. Segundo Dunker define, o "objeto cuja maior expressão subjetiva é a angústia e a perda da forma. Concerne ao objeto $a$ uma gama de experiências de não identidade e de perda de unidade, que Lacan descreveu por meio da noção de gozo" (Dunker, 2018, p. 331).

Não temos como objetivo deste trabalho percorrer detalhadamente o conceito de gozo. Gostaríamos apenas de poder considerar aquilo que nos serve para apresentar o objeto $a$ como uma proposição que ilustra muito bem a ideia de indeterminação nas considerações lacanianas. Sendo assim, o gozo 
é aquele que dá notícias de que há sempre uma tentativa de restituir o objeto perdido e que ela sempre fracassa. Esse resto impossível, "interditado àquele que fala" (Lacan, 1968-69/2008b) está relacionado a um ganho mais imediato, que acaba por modalizar a satisfação. Interditado no sentido daquilo que está entre (vejamos o entre, comparecendo novamente) o dito; composto de intervalo que impacta sobre o desejo e sobre sua lei. O gozo é transgressor e hedonista e tem como campo de referência uma dissolução identitária.

De forma mais desenvolvida, no final dos anos 1960, o conceito de gozo passa a contribuir ainda mais para a construção do conceito de objeto $a$. Como distinto da noção de desejo em psicanálise, é em uma formulação lacaniana que empresta por analogia, a ideia de mais-valia de Marx, que ele aparece em sua versão de mais-de-gozar. De acordo com Lacan, a "função essencial do objeto $a$ " (Lacan, 1968-69/2008b, p. 16). O discurso analítico é justamente o que articula a renúncia a esse usufruto.

É através do conceito de gozo, elemento esse que Lacan (1972-73/1985) refere ser a única substância em psicanálise, que podemos recolher uma denúncia de que a todo momento fracassamos em constituir um ser, um uno. É desse ponto de vista que junto ao conceito de objeto $a$, o gozo participa da 562 proposta lacaniana de apresentar o sujeito como uma experiência pela via do negativo, não como uma unidade, mas como definido por um objeto que se destaca, se desprende e que é a marca de uma insígnia que visa uma abertura, uma indeterminação e não um fechamento em si.

Ao deslocar a noção de sujeito da perspectiva filosófico-cartesiana, para a de um sujeito que aparece como efeito de sua própria incompletude, Lacan retira da categoria de essência, de consistência, a definição mesma da existência, do sou.

Esse traço passa a ser de suma importância porque situa a experiência psicanalítica e por consequência o ato analítico, em uma série que se lê pelas suas brechas, pelas suas quedas, pela sua indeterminação. A escuta fica profundamente marcada pela consideração do que está fora, do para além do simbolizável, ainda que só tenhamos acesso pela via do significante.

\section{Direção do tratamento: objeto $a$ no comando e o analista como puro resto}

Se é verdade que podemos concluir que o ato analítico seria uma forma de não relação no campo do significante, implicaria desde aí, seguindo com Lacan, que o atravessamento dos processos identificatórios se tornasse um 
efeito possível na jornada analisante. No entanto, é preciso desdobrá-lo, já que como mencionamos no início deste estudo, podemos facilmente incorrer em uma perspectiva idealista, como se a queda das identificações fosse o destino final e necessário.

Parece-nos antes mesmo, que a proposta de Lacan foi pensar esse atravessamento como potência motora e, portanto, indeterminada, para a transformação dos modos de relação com o desejo. Como pudemos observar no Grupo de Klein lacaniano, o vazio se encontra na intersecção da negação entre o pensar e o existir (Figura 2). Não à toa, um objeto sem substância, vazio em sua essência, ocupa o lugar de causador do desejo. O objeto acolhe a dimensão indeterminada e se torna potência criadora no movimento desejante.

A queda do sujeito suposto saber denuncia que, para aquele sujeito, um momento produtivo de indeterminação se precipitou e se já não é mais necessário depositar nesse outro a ilusão de completude, então, mesmo que de forma fugidia, é possível ter uma experiência de liberdade já que o amor aparece como pura contingência. De acordo com Carreira (2014),

Lacan vai aos poucos delineando uma modalidade de amor que não é alienante, e que tampouco escraviza. Amor que está num mais além do narcisismo, capaz de romper e esvaziar as identificações imaginárias. Um puro amor. Amor que é pura potência criativa, inovadora. (parag. 12)

Da dissolução dessa operação de amor, surge um resto - o analista. Que alguém ocupe essa posição, implica que esteja advertido das armadilhas que a transferência promove. Em Freud (1912/2018) encontramos a observação de que:

[...] não esqueçamos que são justamente elas [as dificuldades da transferência] que nos prestam o inestimável serviço de tornar manifestas e atuais as moções amorosas ocultas e esquecidas dos pacientes, pois, afinal, ninguém pode ser abatido in absentia ou in effigie. (p. 118)

In absentia ou in effigie, para que não nos enganemos de que há aí uma ausência enquanto positividade, uma imagem que é apenas representacional. Fazer semblante de objeto $a$ não seria ocupar o lugar. Seria, justamente, se prestar a essa condição de indeterminação que a ausência na presença exige e a isto poderíamos relacionar o analista como um veiculador de uma experiência produtiva de indeterminação (Dunker, 2015).

A questão da dissolução da transferência aparece em Lacan como uma travessia. Nos perguntar sobre como se processa uma dissolução (Safatle, 2017) se faz importante nesse movimento entre ato e discurso e também para os encaminhamentos finais deste trabalho. 
Este termo, que remonta tanto à dissolução da escola de psicanálise fundada por Lacan, como também, e aqui sublinhamos este ponto, a dissolução das coordenadas promovidas pela fantasia, acaba por ser determinante para qualquer momento de concluir, seja para os destinos de uma análise ou para o fechamento de uma escrita.

Falar sobre o ato analítico não é outra coisa senão tratar de como se processa a solvência de estados que paralisam um sujeito (Safatle, 2017), tanto em termos de cristalização narrativa, como a própria dissolução da transferência, reportada por Lacan como o momento de passagem de analisante a analista.

Por vezes, algumas dessas dissoluções levam a um fim em si, como a passagem ao ato, por exemplo. Lacan nos diz que o suicídio é o único ato verdadeiro. Uma profunda incapacidade do sujeito de se relacionar e fazer produzir a sua condição de falta-a-ser. No entanto, assim como o ato falho freudiano, o ato analítico também precisa fracassar, diferentemente do suicídio. Fracasso na medida em que comporta uma ruptura que não se encerra em si, mas que rompe com o instituído e relança o desejo a partir de seus efeitos em direção ao novo.

Esse novo pressupõe uma indissociável mudança na estrutura do saber. 564 Isto nos diria que não à toa Lacan apresentou a ideia de revolução ao conceito de ato. Sua intenção era pensar sobre o destino de uma experiência analítica e o fez aproximando o ato psicanalítico da poesia. De acordo com as palavras de Safatle (2017):

Essa é a razão pela qual, do ponto de vista clínico, o conceito de ato analítico acaba por reconfigurar globalmente os processos de intervenção analítica ao secundarizar os mecanismos de simbolização através da inscrição significante produzida pela interpretação. A partir de agora, a análise não irá procurar, através da interpretação, fornecer a inscrição dos sujeitos no interior de um quadro regulado de conflitos e filiações. Ela irá confrontar os sujeitos a um ato que os destituem de um tal lugar. Isso nos explica por que, no dispositivo do ato analítico, vincula-se uma força de dissolução e uma operação de instauração, e toda sua complexidade está exatamente na compreensão desse duplo movimento. (p. 227)

Nesse duplo movimento, se romperiam e se reinstaurariam novas formas de lidar com o mundo. A implicação do sujeito com o desejo que lhe concerne, estaria dada por uma condição menos alienada/submetida ao gozo improdutivo de determinação do Outro. O analista, tendo sido confrontado com essa falta a partir de seu percurso de análise, apareceria como suporte para que uma nova marcha, um novo levante, se desse. Bernardes (2006) assim o descreve: 


\section{ARTIGOS}

A estrutura do discurso do analista tem por agente a função de suscitar o desejo. De um resto que funcionava como gozo opaco, o analista emerge na sua função de causa de desejo, na contingência de um encontro, no acontecimento de um amor. Um amor como profetizou Rimbaud, reinventado. (p. 5)

Para tanto, torna-se necessário sublinhar a questão da reinvenção ao percurso que viemos tentando fazer ao longo deste trabalho. O analista tornado agenciador deste novo, vai sempre aparecer como sobra dessa operação. Por esta via, poderíamos sustentar a hipótese levantada anteriormente, de que uma dimensão de não relação, de condição indeterminada, aparece em cada movimento de passagem do ato ao discurso e o discurso do analista seria uma posição capaz de veicular essa travessia.

\section{Referências}

Barbut, M. (1996). Sobre o sentido da palavra estrutura nas matemáticas. Revista da Letra Freudiana, XV(16), 145-167.

Bernardes, A. C. (2006). Razão poética e laço social. Recuperado de: <http://pepsic. bvsalud.org/pdf/rel/v1n1/v1n1a13.pdf $>$.

Carreira, L. B. (2014). Ruptura e reinvenção: o que Rimbaud tem a nos ensinar sobre o ato. Revista Opinas. Recuperado de: <http://opinias2014.blogspot.com/2014/09/ ruptura-e-reinvencao-o-que-rimbaud-tem.html $>$.

Dissez, N. (2005). Leitura do tetraedro do seminário "O ato psicanalítico". Tempo Freudiano. Associação Psicanalítica. Recuperado de: <http://www. tempofreudiano.com.br/index.php/leitura-do-tetraedro-do-seminario-o-atopsicanalitico/>.

Dunker, C. I. L. (2015). Mal-estar, sofrimento e sintoma: uma psicopatologia do Brasil entre muros. São Paulo, SP: Boitempo.

Dunker, C. I. L. (2018). Crítica da razão diagnóstica: por uma psicopatologia não-toda. In V. Safatle, N. da Silva Jr., \& C. Dunker, Patologias do social: Arqueologias do sofrimento psíquico. Belo Horizonte, MG: Autêntica.

Freud, S. (2010). Obras completas volume 14: "O homem dos lobos" e outros textos. (P. C. de Souza, Trad). São Paulo, SP: Companhia das Letras. (Trabalho original publicado em 1917-1920).

Freud, S. (2018). Fundamentos da clínica psicanalítica (C. Dornbusch, Trad). Belo Horizonte, MG: Autêntica. (Trabalho original publicado em 1912).

Kessler, C. H. (2008). O objeto $a$ é (radical) e não é ([b]analisável). Revista da Associação Psicanalítica de Porto Alegre, 34, 23-32. Recuperado de: <http:// www.appoa.org.br/uploads/arquivos/revistas/revista34-1.pdf $>$. 
Kessler, C. H. (2009). A supervisão na clínica-escola: o ato no limite do discurso (Tese de Doutorado). Centro de Filosofia e Ciências Humanas. Instituto de Psicologia. Universidade Federal do Rio de Janeiro (UFRJ), Rio de Janeiro, RJ, Brasil.

Lacan, J. (1985). O seminário. Livro 20. Mais, ainda. Rio de Janeiro, RJ: Jorge Zahar. (Trabalho original publicado em 1972-73).

Lacan, J. (1992). O seminário. Livro 17. O avesso da psicanálise. (Texto estabelecido por Jacques-Alain Miller). Rio de Janeiro, RJ: Jorge Zahar. (Trabalho original publicado em 1969-70).

Lacan, J. (1998a). A instância da letra no inconsciente ou a razão desde Freud. In Escritos (pp. 496-533). Rio de Janeiro, RJ: Jorge Zahar. (Trabalho original publicado em 1957).

Lacan, J. (1998b). O seminário. Livro 11. Os quatro conceitos fundamentais da psicanálise. (Texto estabelecido por Jacques-Alain Miller. M. D. Magno, Trad.). Rio de Janeiro, RJ: Jorge Zahar. (Trabalho original publicado em 1964).

Lacan, J. (2001). O seminário. Livro 15. O ato analítico. Porto Alegre, RS: Escola de estudos psicanalíticos. (Trabalho original publicado em 1967-68).

Lacan, J. (2005). O seminário. Livro 10. A angústia. Rio de Janeiro, RJ: Jorge Zahar. (Trabalho original publicado em 1962-63).

Lacan, J. (2008a). O seminário. Livro 14. A lógica do fantasma. (A. Lyra, C. B. Fleig, D. A. L. Araújo, I. Chaves, I. Corrêa, L. P. Fonseca, L. A. Tavares, M. L. Q. Santos, M. Fleig, Trad). Recife: Centro de Estudos Freudianos do Recife (CEF). (Trabalho original publicado em 1966-67).

Lacan, J. (2008b). O seminário. Livro 16. De um Outro ao outro. (V. Ribeiro, Trad.). Rio de Janeiro, RJ: Jorge Zahar. (Trabalho original publicado em 1968-69).

Lacan, J. (2009). O seminário. Livro 18. De um discurso que não fosse semblante. (V. Ribeiro, Trad.). Rio de Janeiro, RJ: Jorge Zahar. (Trabalho original publicado em 1971).

Lacan, J. (2016). O seminário. Livro 6. O desejo e sua interpretação. (C. Berliner, Trad.). Rio de Janeiro, RJ: Jorge Zahar. (Trabalho original publicado em 1958-59).

Menegassi, A. (2010). O conceito de destituição subjetiva na obra de Jacques Lacan (Dissertação de Mestrado). Instituto de Psicologia. Universidade de São Paulo (USP). São Paulo, SP, Brasil.

Porge, E. (2009). Transmitir a clínica psicanalitica: Freud, Lacan, hoje. Campinas, SP: Ed. Unicamp.

Rimbaud, A. (1871). “A uma razão". Recuperado de http://www.salamalandro. redezero.org/wp-content/uploads/2007/07/Rimbaud-A-carta-do-vidente-Lettrea\%CC\%80-Paul-De\%CC\%81meny.pdf

Safatle, V. (2017). Lacan, revolução e liquidação da transferência: a destituição subjetiva como protocolo de emancipação política. Estudos Avançados, 31(91), 


\section{ARTIGOS}

211-227. Recuperado de: <https://www.scielo.br/pdf/ea/v31n91/0103-4014ea-31-91-0211.pdf. doi: 10.1590/s0103-40142017.3191016>.

Torres, R. S. (2010). Dimensões do ato em psicanálise. São Paulo, SP: Annablume.

Torres, R. S. (2013). Do ato psicanalítico ao discurso do analista: a estrutura do campo lacaniano (Tese de Doutorado). Instituto de psicologia. Universidade de São Paulo (USP), São Paulo, SP, Brasil.

Vegas, M. Z. (2013). O que faz um psicanalista? uma leitura do seminário $O$ ato psicanalítico de Lacan (Tese de Doutorado). Centro de Filosofia e Ciências Humanas. Programa de Pós-Graduação em Psicologia. Universidade Federal de Santa Catarina (UFSC), Florianópolis, SC, Brasil.

\section{Resumos}

(Analytical act and the clinical power of the undetermined)

This work aims to discuss the connection between the notions of analytical act and indeterminacy in the field of psychoanalytic theory. Based on Lacan's proposition of the analytical act, it highlights the formulation called Klein Group, presented as a transformative sequence and able to illustrate the processes intrinsic to psychoanalytic experience. It takes into account some considerations Lacan extracts from the Cartesian cogito by shifting the category of the subject of positive rationality to that of a decentralized and evanescent subject. Finally, it highlights the indeterminate characteristic of the act as a clinical force that repositions the desiring subject. From the perspective of the treatment's direction, the radical exteriority of the object causes the subject's desire, thus resulting in the analyst as a residue of transformative operations.

Key words: Psychoanalysis, psychoanalytic act, indeterminacy, object $a$

(Acte analytique et puissance clinique de l'indéterminé)

Ce travail vise à discuter, dans le champ de la théorie psychanalytique, une articulation entre les notions d'acte analytique et d'indétermination. Il se base sur la proposition lacanienne de l'acte analytique et met en évidence la formulation appelée Groupe de Klein, présentée comme une séquence transformatrice, capable d'illustrer les processus intrinsèques à l'expérience psychanalytique. Elle imprègne certaines considérations que Lacan extrait du cogito cartésien en déplaçant la catégorie de sujet de la rationalité positive à celle d'un sujet décentralisé et évanescent. Enfin, il met en évidence la caractéristique indéterminée de l'acte comme puissance clinique de repositionnement $d u$ sujet désirant. Dans la perspective du sens de traitement, 
l'extériorité radicale de l'objet provoque le désir du sujet, faisant ainsi de l'analyste un résidu d'opérations transformatrices.

Mots clés: Psychanalyse, acte psychanalytique, indétermination, objet $a$

(El acto analítico y el poder clínico de lo indeterminado)

Este trabajo pretende discutir, en el campo de la teoría psicoanalítica, una articulación entre las nociones de acto analítico e indeterminación. Se parte de la proposición lacaniana del acto analítico para destacar la formulación denominada Grupo Klein, presentada como una secuencia transformadora, capaz de ilustrar los procesos inherentes a la experiencia psicoanalítica. Recurre a algunas consideraciones que Lacan extrae del cogito cartesiano, al desplazar la categoría de sujeto de la racionalidad positiva a la de un sujeto descentrado y evanescente. Finalmente, destaca la característica indeterminada del acto como poder clínico para el restablecimiento del sujeto deseante. En la perspectiva de la gestión del tratamiento, se sitúa la exterioridad radical del objeto causa del deseo del sujeto, resultando así en un analista como residuo de operaciones transformadoras.

Palabras clave: Psicoanálisis, acto psicoanalítico, indeterminación, objeto $a$

Citação/Citation: Adami, F. S., Kessler, C. H., \& Dunker, C. I. L. (2021, dezembro). Ato analítico e a potência clínica do indeterminado. Revista Latinoamericana de Psicopatologia Fundamental, 24(4), 543-569. http://dx.doi.org/10.1590/1415-4714.2021v24n4p543.4.

Editora/Editor: Profa. Dra. Sonia Leite

Submetido/Submitted: 7.12.2020/ 12.7.2020 Aceito/Acepted: 1.2.2021/2.1.2021

Copyright: (C) 2009 Associação Universitária de Pesquisa em Psicopatologia Fundamental/ University Association for Research in Fundamental Psychopathology. Este é um artigo de livre acesso, que permite uso irrestrito, distribuição e reprodução em qualquer meio, desde que o autor e a fonte sejam citados / This is an open-access article, which permits unrestricted use, distribution, and reproduction in any medium, provided the original authors and sources are credited. 


\section{ARTIGOS}

Financiamento/Funding: Este trabalho não recebeu apoio / This work received no funding.

Conflito de interesses/Conflict of interest: Os autores declaram que não há conflito de interesses. / The authors declare that there is no conflict of interest.

\section{Fernanda Souza Adami}

Mestre, Programa de Pós-graduação Psicanálise: clínica e cultura, Universidade Federal do Rio Grande do Sul - UFRGS (Porto Alegre, RS, Br); Psicanalista, Associação Psicanalítica de Porto Alegre - APPOA (Porto Alegre, RS, Br).

Rua Fortunata Zanella,79 - Bom Retiro

89223-056 Joinville, SC, Br

fernandasouzaadami@gmail.com

https://orcid.org/0000-0002-4767-4278

\section{Carlos Henrique Kessler}

Pós-doutor, Universidade de São Paulo - USP (São Paulo, SP, Br); Professor associado, Programa de Pós-graduação Psicanálise: Clínica e Cultura, Universidade Federal do Rio Grande do Sul - UFRGS (Porto Alegre, RS, Br); Psicanalista, Associação Psicanalítica de Porto Alegre - APPOA (Porto Alegre, RS, Br).

Rua Cel. Corte Real, 620/202 - Petrópolis

90630-080 Porto Alegre, RS, Br

carloskessler@yahoo.com.br

https://orcid.org/0000-0002-1318-641X

\section{Christian Ingo Lenz Dunker}

Pós-doutor, Manchester Metropolitan University; Professor Titular, Programa de Pósgraduação e do Departamento de Psicologia Clínica do Instituto de Psicologia - USP (São Paulo, SP, Br); Analista Membro de Escola (A.M.E.) do Fórum do Campo Lacaniano (São Paulo, SP, Br).

Alameda dos Guaiases, 658 - Indianápolis

04078-011 São Paulo, SP, Br

chrisdunker@usp.br

https://orcid.org/0000-0001-7335-4561

This is an open-access article, which permits unrestricted use, distribution, and reproduction in any medium for non-commercial purposes provided the original authors and sources are credited. 